\title{
Research on Low Carbon Economy and Its Consumer Guidance
}

\author{
Dan Zhang
}

Business School, Xi'an Fanyi University, Xi'an, Shaanxi, 710105

Keywords: Low Carbon Economy, Consumer Guidance, Industrial Update

\begin{abstract}
With the global warming, the development of low-carbon economy has become an inevitable choice for China's sustainable development, but also the inevitable trend of the world's future development. The core of developing a low-carbon economy is the implementation of low-carbon social policies, the application of low-carbon technologies and the promotion of low-carbon consumption. Firstly, this paper briefly introduces and compares the consumption patterns, draws the significance of the low-carbon economy paradigm and the concept of low-carbon consumption, and then makes empirical analysis on the inherent relationship between modern consumption patterns and low-carbon economy.
\end{abstract}

\section{Introduction}

The development mode of low-carbon economy will inevitably require the transformation of social consumption patterns. Consumption plays a leading role in the process of economic development. Production decides consumption, but consumption creates demand for production and markets for production. Consumption can not restrict the bottleneck of production underestimate. Low-carbon consumption guides the direction of low-carbon production through real consumer demand, and at the same time, promotes the sustainable development of low-carbon production through the effective realization of consumer demand in the consumer market. "Low-carbon economy" not only means that the production sector should speed up the phase out of backward production capacity with high energy consumption and high pollution, promote scientific and technological innovation in energy conservation and emission reduction, and mean that consumption should reduce waste, save energy and establish a healthy and civilized consumption pattern. In the market supply and demand belong to the buyer's market, how to guide the consumer to adapt to the market environment under the low-carbon economy, to achieve a healthy and civilized low-carbon consumption, it is worth our exploration and research [1].

\section{Low-carbon economy under the guidance of consumption}

Consumer guidance refers to the conscious, reasonable and scientific guidance of human consumption activities, which includes the guidance of social consumption activities and personal consumption activities. Through consumption guidance, the economy is transformed from a high-carbon economy to a low-carbon economy, from a carbonated economy to a carbon economy, and from a low-civilization consumption to a high-civilization consumption.

Through consumption guidance, it is conducive to promoting the development of a low-carbon economy, transforming the economy from "high carbon" to "low carbon", from "carbonizing" to "carbon" and promoting sustainable social development. As a brand new economic development mode, low-carbon economy requires reducing energy consumption rate and realizing green development of economy. Consumption as an important link in social production must be compatible with it. Consumption of green products and consumption of low-energy products are good Spending habits and preferences [2]. The socio-economy built on the basis of industrial economy has a high degree of economic carbonization due to the heavy use of carbon-containing energy sources, surpassing the carrying capacity of the environment, causing serious environmental pollution and affecting the social and economic sustainable development. Through consumption guidance, Make the structure of social production and consumption structure shift from high carbon 
to low carbon, reduce the production and consumption of carbonized products, and achieve economic restructuring and sustainable development. In the past, due to the lack of material formation of a strong consumer motivation, but the lack of reasonable guidance in the process of consumption, leading to self-consumption in the process of self-formed a lot of bad habits, such as "excessive consumption", "conspicuous consumption", "One-time consumption", "convenient consumption" and so on. These consumption habits and behaviors have brought serious pollution and waste to the economy and society, causing serious environmental damage. Therefore, the development of low-carbon economy must guide consumption. Good consumer guidance, the formation of good "social orders," will surely promote the development of productive forces. The necessary advance consideration and global consideration of the development of consumption can drive the development of productive forces toward the future needs and overcome the blindness and backwardness that may arise in the spontaneous development of consumption. Through consumption guidance, changing people's consumption concept and forming good consumption habits and preferences, it can promote the change of consumption structure in favor of developing low-carbon economy, promote the rational adjustment of production layout and realize the goal of "carbonization" from "carbon" Economic transformation means not only lowering the carbonization degree of the economy but also enabling the carbonization to be decomposed so that the readjustment of the production structure can meet the needs of the "two-type" social construction and achieve sustainable social development[3].

Through the guidance of consumption, improve consumer's quality of consumption, to achieve consumption from "low civilization" consumption to "high civilization" consumption change, and promote people's all-round development. At the 1994 International Conference on Population and Development in Cairo, the Program of Action, jointly identified by 179 countries, set forth a new concept of "man's all-round development" and set the goal of a coordinated and sustainable development of population, economy, social resources and the environment. The all-round development of people is the ultimate goal of all economic construction and social development. In a sense, the essence of mankind's pursuit of an ideal society is the pursuit of human development, and the development of society in the final analysis is the development of human beings. The process of man's all-round development is consistent with the goal of man's development. , The coordinated development of society, and the goal of realizing the all-round development of mankind and each of its individualities. " With the development of a low-carbon economy and the realization of a recycling economy and a sustainable development of the society and economy, the ultimate goal of development remains the all-round development of people. Consumption habits such as "convenience consumption", "quick consumption", "one-time consumption" and "conspicuous consumption" formed on the basis of industrial economy in the past have caused a heavy burden on the environment and have in turn affected human survival and development. It can be said that this mode of consumption is a low civilized consumption. Through the guidance of consumption, constantly changing the consumer demand for consumption, both material and spiritual consumption can be developed from a low level to a high level, so that they will have a new pursuit; through consumer guidance so that they can form a good consumer habits, Accept low carbon consumption, support recycling consumption, realize the coordinated development of consumption, nature and society, and continuously improve their own literacy so as to promote their overall progress [4].

\section{Modern consumption patterns and low-carbon economy interaction}

Any kind of economic development mode inevitably has an impact on the mode of social production and consumption. This is already the case with the low-carbon economy. From the point of view of material assurance of consumption, consumption depends on the economic operation centered on the value of reproduction, that is, production determines consumption. On the contrary, from the perspective of economic conditions and market guarantee, economic operations depend on consumption. From the current energy-consuming and extensive type to the technology-intensive, resource-saving and environment-friendly direction, leading to changes in the layout of social 
industry structure, whether it is between the three industries or within the industry will make adjustments, which It will also affect the consumption structure based on the industrial economy. On the one hand, the emphasis of consumption will shift from high-energy-consuming and high-pollution industries to environmentally-friendly industries. On the other hand, consumer preferences will also change as the production layout changes, favoring products with lower energy consumption.

Low-carbon economy will change the concept of consumption. With the introduction and development of the low-carbon economy, the impact on consumer demand and consumption patterns will also change consumer's existing concepts, consumption of "quick consumption", "one-time consumption" and "conspicuous consumption" Concepts and habits will change with changes in the economic base. Consumer attitudes such as "learning consumption", "green consumption" and "healthy consumption" will gradually take shape, with the tendency of pursuing healthy consumption as consumption. Low-carbon economy will change consumer demand. The development of a low-carbon economy is a tremendous accumulation of technology and capital, requiring the improvement of production efficiency and the reduction of resource consumption per unit of production value. In order to adapt to the development of low-carbon economy, enterprises must improve recycling and utilization of waste through technological progress so as to achieve "low-carbon" and "carbonization" and recycling of the economy, and provide low-carbon products to society Consumer demand. The requirements for the development of a low-carbon economy will prompt the government to transform its functions, improve the government's social management and public service capabilities, provide more and better environmental-friendly public goods to the public, and provide a good consumption environment for low-carbon products. The government will transform the existing Some mode of operation [5].

\section{Low-carbon economy under the consumption pattern of transformation and guidance strategy}

Low-carbon consumption is a better way to improve the quality of life of consumption. Improving the quality of life means not only the material satisfaction but also the improvement of the quality of the environment. In today's increasingly scarce environmental resources, low-carbon consumption is the better way to improve the quality of life. We can envisage starting from these aspects as a way to shift to a low-carbon economy and a low-carbon life. First, we should eliminate the "convenience spending" hobby at the expense of high energy consumption. The second is to use "associated energy saving awareness" to get rid of the use of "one-time" supplies consumer tastes. Third, we should give up the hobby of "face consumption" and "luxury spending" at the expense of a large amount of energy consumption and the massive emission of greenhouse gases. Citizens' participation in low-carbon consumption patterns needs to pay attention to "5A": First, Awareness (cognition), which means understanding and understanding of low-carbon consumption patterns; second, Availability (practicality), that is, practicality of low-carbon consumption patterns And the effectiveness of reducing greenhouse gas emissions; third, Accessibility (operability), that is, the operability of low-carbon consumption patterns; Fourth, Affordability (affordable), that is, the economic cost of low carbon consumption can be affordable ; Fifth, Acceptance (acceptability), that is, in the moral values and safety and reliability of social acceptance. Undoubtedly, the way in which citizens consume will add up to a few drops and become the "vane" of social values in the new era.

To achieve low-carbon consumption of productive enterprises is a long-term and arduous task that requires enterprises to have a sense of social responsibility for emission reduction and to invest capital and human resources to reduce carbon emissions per unit of energy consumption of enterprises through technological innovation so that enterprises In the process of production and consumption, the energy structure tends to be diversified and the industrial structure is upgraded. At the same time, enterprises are also the main suppliers of low-carbon consumer products and a bridge linking low-carbon productive consumption to low-carbon non-productive consumption. Only when enterprises provide low-carbon energy-saving consumer goods enable the public to buy 
products in supermarkets or other shopping malls, The degree of low carbonation has the choice, in order to have a more extensive and in-depth implementation of the material basis of low-carbon consumption patterns of the people.

Social organizations to promote low-carbon consumption. Social organization is an important subject in the modern multi-governance structure and plays an irreplaceable role in promoting the universalization of low-carbon consumption patterns. Its distribution and depth of all sectors of society, with its own advantages of the layout than the government to carry out more extensive and in-depth energy-saving emission reduction, low-carbon economy, publicity and education activities; the same time, for example, the environmental protection organization itself is a very important social organization, This shows that social organizations will be more receptive to the concept of low-carbon consumption, and actively practice and enthusiasm to promote. Government leads low-carbon consumption. China's low-carbon economy has passed the policy of oaths and the concept of market speculation. The government has begun to lay a solid foundation in practice and enterprises have begun pragmatic deeds to tap the economic benefits behind low-carbon development. The idea of relying on low-carbon development to transform the mode of economic growth has become increasingly clear. From a global perspective, the government should lead low-carbon consumption from these aspects: First, cultivate a low carbon awareness of the whole nation and create a low-carbon consumption culture. Second, improve the government's regulatory policies to encourage low-carbon consumption. Third, government agencies should start from themselves to take the lead in energy conservation and emission reduction. Government departments and units set an example for other departments through measures such as early adoption and purchase of the latest advanced technologies and products.

\section{Conclusions}

Socio-economic changes and changes based on a low-carbon economy will inevitably bring about changes in the superstructure, and will also affect people's consumption attitudes and patterns of consumption. Only through constant consumer guidance can various consumer subjects in society have the awareness of civilized consumption in order to achieve the transition from "high carbon economy" to "low carbon economy", "carbonation" economy to "carbon" economy, the transition from low civilization consumption to high civilization consumption, so as to eventually achieve the harmony between human consumption and natural ecology.

\section{References}

[1] Zhao Jinwen, Fan Jitao. An Empirical Study on the Inner Compliance of Economic Growth and Energy Consumption [J]. Journal of Economic Research, 2007 (8): 21-23

[2] Wu Qiaosheng, Chen Liang, Zhang Yantao, Cheng Jinhua. Reevaluation of the relationship between China's energy consumption and GDP [J]. Journal of Quantitative \& Technical Economics, 2008 (6): 77-81

[3] Zhuang Guiyang. China's development of low-carbon economy difficulties and obstacles [J]. Jiangxi Social Sciences, 2009 (7): 32-35

[4] Chen Xiaochun, Tan Juan, Chen Wenjie. On low-carbon consumption patterns [N]. People's Daily, 2009: 4- 21

[5] Zhang Li. Innovation of Consumption Patterns and Extension of "Human Nature" Theory [J]. Journal of Beijing Technology and Business University (Social Science Edition), 2001, (6): 10-12. 